\title{
O etnógrafo e o jornalista: o olhar e a escuta como ferramentas de trabalho
}

\author{
Karina Galli Fraga da Silva \\ Universidade Federal do Mato Grosso (UFMT) - E-mail: gallif.karina@gmail.com \\ Jornalista e mestre em estudos de Cultura Contemporânea
}

\begin{abstract}
Resumo
O presente artigo apresenta uma reflexão acerca da semelhança entre os trabalhos dos profissionais jornalista e etnógrafo. Partindo da antropologia, principalmente do trabalho de Clifford Geertz, faz-se uma analogia entre a descrição densa, método etnográfico de que fala 0 autor, e a reportagem, forma de narrativa jornalística que se diferencia do simples relato noticioso pelo tratamento mais criativo e elaborado do texto. A questão da interpretação e da subjetividade, próprias da etnografia e, portanto, do trabalho antropológico, visa a construção de uma leitura do que acontece. Do mesmo modo, na reportagem reinterpreta a realidade percebida ao captar o real sob múltiplos ângulos e observações. Em ambas as atividades, o que se vê é um constante ir e vir entre observador e o observado.
\end{abstract}

\section{Palavras-chave}

Reportagem, etnógrafo, jornalista, interpretação

\begin{abstract}
The present paper shows a reflection about the similarity between the work of the journalist and the ethnoprapher. Starting from anthropology, mainly from the work of Clifford Geertz, it is done an analogy between the "thick description", the ethnographic method used by the author, and the report, the journalistic narrative that differs from the simple news story because of the more creative and elaborated treatment of the text. The question of interpretation and subjectivity, common in an ethonography and, therefore, in the anthropological work, aims the construction of a reading of what happens. Likewise, in the journalistic report there is a reinterpretation of the perceived reality, by collecting the real under multiple angles and observations. In both activities, one can see a constant coming and going between observer and observed.
\end{abstract}

\section{Keywords}

Report, ethnographer, journalist, interpretation

Artigo recebido em 20/03/2013

Aprovado em 24/05/2013 
Q uando Geertz decidiu estudar a sociedade balinesa, ele o fez movido por uma curiosidade em estudar uma cultura diferente da sua, em contar aos norteamericanos as suas impressões daquela gente. Ao analisar as aldeias, percebeu que uma rinha de galos revelaria grande parte de Bali, pois "é apenas na aparência que os galos brigam ali - na verdade, são os homens que se defrontam" (GEERTZ, 1989, p.283). Essa compreensão só foi possível porque o etnógrafo em questão lançou mão de ferramentas básicas para tal trabalho: o olhar e a escuta. Só através desses sentidos, ou melhor, do aguçamento deles, é que ele teve a habilidade de enxergar para além dos fatos. Muito já se tinha estudado sobre o local: sua mitologia, sua arte, seus rituais, sua organização social, porém as brigas de galos eram pouco mencionadas. Talvez por um olhar domesticado, que só vê o que quer. Em vez de transformar o outro em folclore, Geertz nos deu outra versão dele: "Se olha para Bali não apenas através de sua dança, de suas peças de sombras, de sua escultura e de suas moças, mas também através de suas brigas de galos." (op. cit p.320).

É nesse aspecto que o trabalho do jornalista se assemelha ao do etnógrafo. Ele precisa saber olhar e escutar para escrever uma bela história. Se livrar dos clichês e dos padrões para proporcionar ao leitor uma nova versão de um fato por vezes tão explorado. É resistir à domesticação do olhar e desconstruir o que está posto. Mas isso não é fácil. O drama contemporâneo da invisibilidade nos ensurdece. Vemos, mas não enxergamos, ouvimos, mas não escutamos. A pressa no fechamento das matérias pasteuriza os textos, os tornam iguais. As pautas estão sempre prontas, é só mudar o quê, o como, o quando e o onde. Ora, se todos veem as coisas da mesma forma, então não são necessários mais do que uns poucos jornalistas por redação.

A dificuldade em treinar o olhar nos remete à famosa constatação de Boas, que diz que o olho que vê é sempre o olho da tradição, ou seja, eu só olho para aquilo que é comum a mim, com o qual eu me identifico. Todo o resto é alteridade, diferença, logo, a estranheza. As relações com o outro carregam sempre o tom da identidade e diferença. 
Estudos em Jornalismo e Mídia - Vol. $10 \mathrm{~N}^{\circ} \mathrm{I}$ - Janeiro a Junho de 2013

O outro é tudo aquilo que não sou, é alguém diferente de mim. Logo, as representações de mim e do outro mantêm conexões com relações de poder. Para Tadeu Tomaz (2000, p.81).

A afirmação da identidade e a enunciação da diferença traduzem o desejo dos diferentes grupos sociais, assimetricamente situados, de garantir o acesso privilegiado aos bens sociais. A identidade e diferença estão, pois, em estreita conexão com relações de poder. $\mathrm{O}$ poder de definir a identidade e de marcar a diferença não pode ser separado das relações mais amplas do poder. A identidade e a diferença não são, nunca, inocentes.

Ao propor o desenvolvimento de uma ciência da cultura, Tylor (1871) acreditava que todas as sociedades estariam dispostas numa única escala evolutiva ascendente, em diferentes estágios de desenvolvimento cultural. A confusão entre cultura e civilização remete a um imaginário etnocêntrico, que vê a cultura ocidental européia - como "alta" e que, portanto, estaria acima das demais, as quais um dia poderiam ascender. Sem hierarquizar, Geertz propõe analisar a desordem, a cultura enquanto uma sequência desconexa a ser desvendada. E, através da hermenêutica ${ }^{1}$, tentar compreender e não se preocupar em explicar.

Essa é a tarefa do jornalista: interpretar os relatos de seus informantes e criar uma narrativa a partir deles de modo a aproximar mundos. Tal aproximação de mundos é, aliás, um exercício do qual também se valem os etnógrafos. A partir da fusão de horizontes - seu e do grupo ou do indivíduo analisado - eles se situam entre o estranho. Esse processo, contudo, não requer abandono do próprio mundo do etnógrafo, mas implica na penetração do horizonte do outro. No caso do repórter, a imparcialidade preconizada do relato jornalístico é desmitificada, pois enquanto sujeito dotado de emoções e sentimentos, ao adentrar o universo do outro, ele se modifica ao mesmo tempo em que modifica o outro. Nesse sentido, a pesquisa etnográfica, assim como a

\footnotetext{
${ }^{1}$ Hermenêutica é um ramo da filosofia que estuda a teoria da interpretação. A hermenêutica moderna ou contemporânea engloba não somente textos escritos, mas também tudo que há no processo interpretativo. Isso inclui formas verbais e não-verbais de comunicação, assim como aspectos que afetam a comunicação, como preposições, pressupostos, o significado, a filosofia da linguagem e a semiótica.
} 
reportagem, pode ser tomada enquanto experiência pessoal.

Situar-nos, um negócio enervante que só é bem-sucedido parcialmente, eis no que consiste a pesquisa etnográfica como experiência pessoal. Não estamos procurando, pelo menos eu não estou, tornar-nos nativos ou copiá-los. O que procuramos, no sentido mais amplo do termo, que compreende muito mais do que simplesmente falar, é conversar com eles, o que é muito mais difícil, e não apenas com estranhos, do que se reconhece habitualmente. (GEERTZ, 1989, p.23)

A etnografia, para Geertz, consiste em um esforço intelectual para a descrição densa e essa descrição é sempre interpretativa, microscópica e inesgotável. Os antropólogos trabalhariam com essa ferramenta quase como um contra-método, incorporando a história do pesquisador enquanto sujeito do seu próprio tempo. Fariam, então, um retrato de como as coisas são do ponto de vista da imaginação. Imaginação cimentada na análise dos veículos que transmitem significados. A semiótica desponta, então, como influência da antropologia interpretativa e a análise da cultura passa a se debruçar na análise da produção dos sentidos.

Para analisar veículos que transmitem significados e que, portanto, dizem muito da cultura e da vida de um povo, o repórter, da mesma forma que o etnógrafo, precisa se inserir na vida e na rotina do grupo analisado e, convivendo com eles, eleger o(s) detalhe(s) que revela(m) muito do mundo daquele grupo. $O$ ofício desses profissionais é, portanto, olhar uma cultura enquanto (con)texto, que precisa ser lida e interpretada, de modo que essa interpretação é sempre de segunda e terceira mão, pois como explica Geertz (op. cit. p.30) "o que inscrevemos não é o discurso social bruto ao qual não somos atores, não temos acesso direto a não ser marginalmente, mas apenas àquela pequena parte dele que os nossos informantes nos podem levam a compreender".

Sobre isso, é importante citar aquele que foi o pai da etnografia e que foi buscar em ilhas longínquas e com território delimitado alguma semelhança conosco. Malinowski dizia que na etnografia embora as fontes sejam facilmente acessíveis, elas são dúbias e complexas e não se encontram materializadas em documentos fixos e concretos. Por isso, a distância entre o material bruto coletado e a apresentação final dos 
Estudos em Jornalismo e Mídia - Vol. $10 \mathrm{~N}^{\circ} \mathrm{I}$ - Janeiro a Junho de 2013

resultados. Situação semelhante ao dia a dia do jornalista, que busca, através de vestígios do observado, construir sua história.

$\mathrm{Na}$ etnografia, o autor é ao mesmo tempo, o seu próprio cronista e historiador; suas fontes de informação são, indubitavelmente, bastante acessíveis, mas também extremamente enganosas e complexas; não estão incorporadas a documentos materiais fixos, mas sim ao comportamento e memória de seres humanos. Na etnografia, é frequentemente imensa a distância entre a apresentação final dos resultados da pesquisa e o material bruto das informações coletadas pelo pesquisador através de suas próprias observações, das asserções dos nativos, do caleidoscópio da vida tribal (MALINOWSKI, 1976, p.22-23).

Retomando Boas, que defende a ideia de desenvolvimentos culturais diferentes e independentes, e que por isso se distancia do evolucionismo cultural de Tylor, as culturas são dinâmicas e há uma unidade psíquica dos povos. Para ele, a complexidade dos fatos culturais dificulta as generalizações e a formulação de leis, pois cada cultura segue os seus próprios caminhos em função dos diferentes eventos históricos que enfrentou. Com isso, a explicação evolucionista da cultura só tem sentido quando ocorre em termos de uma abordagem multilinear ${ }^{2}$. É esse o grande desafio das ciências sociais e humanas: promover discussões minuciosas lançando luz sobre temáticas reveladoras dos fenômenos sociais. Como disse Geertz (op. cit. p.38) a respeito dos objetivos da etnografia: "tirar grandes conclusões a partir de fatos pequenos, mas densamente entrelaçados".

Conversar com eles: é este o ponto global da abordagem semiótica da cultura que nos auxilia a ganhar acesso ao mundo conceitual no qual vivem os sujeitos analisados. E é essa também a metodologia do jornalismo. Porque a escuta é sempre afeto e saber escutar é não querer apenas encaixar a minha tese nas histórias dos meus personagens.

Em palestra no Congresso Regional de Estudos Interdisciplinares em

\footnotetext{
${ }^{2}$ Em oposição à teoria evolucionista, Franz Boas foi o precursor da ideia de que cada grupo humano desenvolve-se através de caminho próprio, que não pode ser simplificado na estrutura dos estágios selvageria, barbarismo e civilização. É disso que trata a abordagem multilinear da cultura (LARAIA, p.114)
} 
Comunicação na Universidade Federal de Mato Grosso ${ }^{3}$, a jornalista Eliane Brum ${ }^{4}$ falou sobre a busca do personagem singular e enfatizou a ferramenta essencial do jornalismo: "Escutar, escutar e escutar". As pessoas valorizam muito as perguntas, mas esquecem que tem de aprender a escutar as respostas. E saber escutar corresponde a prestar atenção ao que não é dito, porque quando uma pessoa para de falar, ela continua nos dizendo algo. Há coisas que só são contadas pelo silêncio.

É aí que se aproximam os modos de atuar do etnógrafo e do jornalista. Em cada detalhe, no banal, no repetitivo e no desinteressante. É isso o que importa e que dá meios de desvelar a realidade. A escolha de determinada palavra e não de seu sinônimo, a casa da pessoa, o que ela mostra e o que ela não mostra do seu mundo, tudo é importante e nos diz algo. E para ser capaz de apreender tudo, é importante estar vazio, aberto e entregue para olhar e escutar o mundo do outro e ser preenchido por ele. Sem esquecer de que não somos apenas razão e de que não há como nos despir da carga emocional que nos é própria. Para José Marques de Melo, a grande motivação profissional do jornalista é o direito de emitir também seus pontos de vista sobre os acontecimentos que presencia ou analisa, deixando de ser mero figurante no cenário da atualidade e assumindo-se como protagonista.

A questão da objetividade, perseguida pelo jornalismo e onipresente nos manuais de redação, pretende reproduzir o real, por intermédio da lente de aumento da imprensa, sendo fiel aos acontecimentos e permitindo, assim, que eles ganhem repercussão pública exatamente como ocorreram. O que não se pontua é que o simples fato de selecionar o que entra no jornal, a capa, as manchetes, tudo se configura enquanto opinião, visão de mundo.

Os jornais, em sua origem, são opinativos e não informativos. $\mathrm{Na}$ origem, emitem visão política doutrinária e crítica, até o momento em que a notícia assume

\footnotetext{
${ }^{3}$ O Congresso de Ciências da Comunicação da região Centro-Oeste - Intercom - aconteceu na UFMT, no período de 08 a 10 de junho de 2011.

${ }^{4}$ Eliane Brum é jornalista, escritora e documentarista. Trabalhou por onze anos no Zero Hora, de Porto Alegre. É repórter especial da Época desde 2000 e autora dos livros: Coluna Prestes - O Avesso da Lenda, A Vida Que Ninguém Vê e O Olho da Rua.
} 
papel preponderante nos meios e absorve a prioridade dos jornais.

Usualmente, como modelo dos jornais ingleses e norte-americanos, os jornais brasileiros passaram a usar a página editorial para separar a opinião da informação. Juarez Bahia diz, entretanto, que a restrição noticiosa, a discriminação noticiosa, a omissão noticiosa e a autocensura são formas de editorializar a notícia fora da página de opinião. "A separação definitiva entre notícia e opinião tende a demonstrar na página editorial a crença na utilidade da opinião" (BAHIA, 1990, p.107).

Em relação a essa pretendida objetividade diante do trabalho científico, Geertz (op. cit. 40) afirma: "Nunca me impressionei com o argumento de que, como é impossível uma objetividade completa nesses assuntos, é melhor permitir que os sentimentos levem a melhor".

\section{Jornalistas e etnógrafos: caçadores}

Antes de decidir ser jornalista ou etnógrafo, o homem foi caçador. E durante esse tempo ele "aprendeu a reconstruir as formas e movimentos das presas invisíveis pelas pegadas na lama; aprendeu a farejar, registrar, interpretar e classificar pistas como fios de barba; aprendeu a fazer operações mentais complexas com rapidez fulminante" (1989, p.151). Todo esse saber, de que trata Carlo Ginzburg em seu "Mitos, emblemas e sinais", é próprio de um paradigma indiciário ${ }^{5}$, baseado na semiótica, que começou a se firmar nas ciências humanas no final do século XIX. Contrariamente à ciência positivista, calcada no emprego da matemática e do método experimental que exigem quantificação e repetibilidade dos fenômenos, o paradigma do caçador adota uma perspectiva individualizante, analisa as minúcias para desvendar um fato.

Nesse ponto, abriam-se duas vias: ou sacrificar o elemento individual à generalização, ou procurar, elaborar, talvez às apalpadelas, um paradigma diferente, fundado no conhecimento científico do individual. A primeira via foi percorrida pelas ciências naturais, e só muito tempo depois pelas ciências humanas. O motivo é evidente. A

\footnotetext{
${ }^{5}$ Segundo o autor, até agora não se prestou suficiente atenção a esse modelo epistemológico (p. 143).
} 
tendência a apagar os traços individuais de um objeto é diretamente proporcional à distância emocional do observador. (idem, p.163)

O que caracteriza esse saber do tipo venatório é a capacidade de, a partir de dados aparentemente negligenciáveis, remontar a uma realidade complexa não experimentável diretamente. É esse tipo de olhar que permite ao autor relacionar Freud, Arthur Conan Doyle e Giovani Morelli. Este parece ter influenciado diretamente o que fizeram aqueles. Morelli foi um historiador de arte italiano que desenvolveu um método de críticas de obra de arte que buscava identificar características de um estilo artístico individual através de uma análise minuciosa, conferindo atenção aos detalhes. Esses dados marginais, afirma Ginzburg, eram reveladores porque constituíam os momentos em que o controle do artista, ligado à tradição cultural, distendia-se para dar lugar a traços puramente individuais. A alusão a uma atividade inconsciente é reveladora porque permite identificar o núcleo íntimo da individualidade artística com os elementos subtraídos ao controle da consciência.

O método morelliano ou indiciário influenciou Freud antes mesmo da descoberta da psicanálise. Ginzburg, se referindo a Freud, diz que a proposta de um método interpretativo centrado sobre os resíduos, sobre os dados marginais, os pormenores normalmente considerados sem importância ou até triviais, baixos, forneciam a chave para aceder aos produtos mais elevados do espírito humano. Dizia Morelli,

(...) é preciso não se basear, como normalmente se faz, em características mais vistosas, portanto mais facilmente imitáveis, dos quadros: os olhos erguidos para o céu dos personagens de Perugino, o sorriso dos de Leonardo, e assim por diante. Pelo contrário, é necessário examinar os pormenores mais negligenciáveis, e menos influenciados pelas características da escola a que o pintor pertencia: os lóbulos das orelhas, as unhas, as formas dos dedos das mãos e dos pés. (GINZBURG, 1989, p.144)

Da mesma forma, o criador de Sherlock Holmes, Arthur Conan Doyle, também se aproximou do método indiciário para construir o método do detetive Holmes. O detetive é comparável ao conhecedor de arte ao descobrir o autor do crime baseado em 
indícios imperceptíveis para a maioria. As pegadas na lama, as cinzas de cigarro, os lóbulos das orelhas, tudo é importante para Holmes.

Nessa tripla analogia descrita - Morelli, Freud, Doyle -, pistas mínimas talvez possam captar uma realidade mais profunda, de outra forma inatingível. Essas pistas teriam uma nomenclatura distinta em cada caso: para Morelli, eram signos pictóricos; para Freud, sintomas; e para Holmes, indícios (GINZBURG, op. cit. p.150).

A perspicácia do olhar, própria dos exemplos acima citados, é a ferramenta de que se valem os etnógrafos e os jornalistas. Estes são, antes de tudo, investigadores, que precisam enxergar indícios, interpretar fontes. A investigação, aliás, é uma prática cada vez menos adotada pelos jornalistas. Eles preferem escrever a partir dos relatos das chamadas fontes oficiais - Ministério Público, Polícia, Defensoria, Tribunal de Justiça etc $-\mathrm{a}$ investigar e buscar fontes novas para construir novas histórias.

O emblemático caso "Watergate", em que dois jornalistas americanos investigam a relação de dois fatos aparentemente desconexos e desvendam o caso de corrupção mais famoso dos Estados Unidos, culminando com a renúncia do então presidente Richard Nixon, mostra que as fontes representam o cerne do trabalho jornalístico e que sem elas essa atividade não pode ser concluída com sucesso. Além de muita dedicação e paciência, o bom jornalista deve saber preservar suas fontes. Um fato sem nenhuma relevância aparente pode se transformar na maior reportagem do século.

Ao selecionar o que é relevante, o que tem atributos capazes de identificar certo fenômeno, o etnógrafo e o jornalista se valem do método morelliano de trabalhar com o não-óbvio. E antes de Morelli, eles se assemelham a caçadores, que foram os primeiros, de acordo com Ginzburg, a "narrar uma história", pois eram capazes de ler, nas pistas mudas - se não imperceptíveis - deixadas pela presa, uma série coerente de eventos.

\section{Reflexões (in)conclusivas}

A tentativa de aproximar o trabalho do jornalista e do etnógrafo é, antes de 
tudo, uma tentativa de descrever a organização da experiência e da ação humana por meios simbólicos. É a cultura, propriamente dita, que permite que as pessoas, relações e coisas que povoam a existência humana manifestem-se como valores e significados. Significados esses que não podem ser determinados a partir de propriedades biológicas ou físicas. Segundo Laraia,

O homem é o resultado do meio cultural em que foi socializado. Ele é um herdeiro de um longo processo acumulativo, que reflete o conhecimento e a experiência adquiridas pelas numerosas gerações que o antecederam. A manipulação adequada e criativa desse patrimônio cultural permite as inovações e as invenções. Estas não são, pois, o produto da ação isolada de um gênio, mas o resultado do esforço de toda uma comunidade. (LARAIA, 2009, p.45)

Relembrando o seu professor Leslie White, que dizia que um macaco não é capaz de apreciar a diferença entre água benta e água destilada, Marshall Sahlins (1997, p.41) pontua que essa ordenação (e desordenação) do mundo em termos simbólicos é capacidade singular da espécie humana. É nesse sentido que o estudo da(s) cultura(s) desponta relevante nas ciências humanas, e os trabalhos do etnógrafo e do jornalista se cruzam enquanto profissionais que tecem o tecido social e que promovem um "alargamento do universo do discurso humano", nas palavras de Geertz (op. cit. p.24).

A raiz etimológica da palavra "etnografia" reside nos vocábulos gregos etnos, povo, e grapho, descrever. Descrever um povo, eis o exercício do pesquisador que se vale desse método. Aparentemente simples, os livros-texto tratam a etnografia enquanto uma prática de estabelecer relações, selecionar informantes, transcrever textos, levantar genealogias, mapear campos, manter um diário e assim por diante (GEERTZ, 1989, p.15). A etnografia, no entanto, não se resume às técnicas utilizadas, ela requer um esforço intelectual muito semelhante ao esforço dos jornalistas, ao empreender uma reportagem. Esse exercício não se encontra nos manuais de redação, porque se trata de interpretação, de subjetividade, de proposição de narrativas. Em outras palavras, trata-se de contar histórias. Brene Brown", pesquisadora norte-americana, afirma que "as

\footnotetext{
${ }^{6}$ Brene Brown é professora e pesquisadora na Universidade de Houston, na Faculdade de Serviço Social. Ela estuda as conexões humanas - nossa capacidade de empatia, pertencimento e amor.
} 
Estudos em Jornalismo e Mídia - Vol. $10 \mathrm{~N}^{\circ} \mathrm{I}$ - Janeiro a Junho de 2013

conexões e as narrativas é o que dá sentido a nossas vidas.” E contam-se histórias em paredes de cavernas, nos ritos dos xamãs de várias tribos, nos papiros chineses, nas pirâmides do Egito, nas peças de Shakespeare, nas praças de Cuiabá. É isso o que nos faz humanos segundo Neil Gaiman, a vontade de contar histórias.

\section{Referências Bibliográficas}

BROWN, Brene. The Power of vulnerability. TedxHouston, junho de 2010. Disponível em: $<$ http://www.ted.com/talks/lang/eng/brene brown on_vulnerability.html $>$ Acesso em 20/05/2011.

BRUM, Eliane. O Olhar e escuta na busca do personagem singular. Oficina Laboratório Itaú Cultural. In: Congresso de Ciências da Comunicação na região Centro-Oeste. Cuiabá, 2011.

BAHIA, Juarez. Jornal, História e Téenica - História da Imprensa Brasileira. São Paulo: Ática, 1990.

FRANZ, Boas. Antropologia Cultural. Rio de Janeiro: Jorge Zahar Ed. 2004. p.87-109.

GEERTZ, Clifford. A interpretação das culturas. Rio de Janeiro: LTC Editora, 1989.

GINZBURG, Carlo. Sinais: raízes de um paradigma indiciário. In: Mitos, emblemas, sinais: morfologia e história. São Paulo: Companhia das Letras, 1989.

LARAIA, Roque de Barros. Cultura: um conceito antropológico. Rio de Janeiro: Jorge Zahar Ed., 2009.

MALINOWSKI, Bronislaw. Os argonautas do pacífico Ocidental. In: Os pensadores. Abril Cultural. São Paulo: Abril S.A. Cultural e Industrial, 1976.

MELO, José Marques de. Teoria do jornalismo: identidades brasileiras. São Paulo: Paulus, 2006.

SAHLINS, Marshall. O "pessimismo sentimental" e a experiência etnográfica: Por que a cultura não é um "objeto" em via de extinção (PARTE I) In: Mana v. 3 n.1 Rio de Janeiro, abril de 1997. Disponível em: $<$ http://www.scielo.br/scielo.php? script=sci_arttext\&pid=S010493131997000100002\&lng=pt\&nrm=iso\&tlng=pt $>$ Acesso em 25/04/2011.

SILVA, T. T. da. A produção social da identidade e da diferença. In: Silva, T. T. da (Org.). Identidade e Diferença: a perspectiva dos estudos culturais. Petrópolis: Vozes, 2000.

TYLOR, Edward Burnett. A Ciência da Cultura. In: Evolucionismo Cultural: textos de Morgan, Tylor e Frazer. Rio de Janeiro: Jorge Zahar Ed., 2005. p.69-99.

Este artigo e todo o conteúdo da Estudos em Jornalismo e Mídia estão disponíveis em http://www.periodicos.ufsc.br/index.php/jornalismo/index

Estudos em Jornalismo e Mídia está sob a Licença Creative Commons. 